To the Editors:

\title{
A woman with dengue encephalitis
}

Ceylon Medical Journal 2013; 58: 130

We read with interest the leading article on the pathogenesis of severe dengue infection, especially the section on organ involvement [1].

We wish to report a patient with dengue complicated by encephalitis. Virus isolation from brain tissue and CSF of patients with neurological symptoms and the presence of IgM antibody to dengue in CSF suggest direct virus invasion of the CNS [2].

A 42-year old woman was admitted with 4 days of fever associated with headache, arthralgia and vomiting. On admission she was alert, febrile, flushed and had a 3 $\mathrm{cm}$ tender hepatomegaly. She had leucopenia and thrombocytopenia. Three days later her consciousness level started to deteriorate. On the fourth day she developed status epilepticus. Examination after control of seizures revealed that she had a GCS level of 7/15, normally reacting pupils and conjugate deviation of eyes with nystagmus to the right. Furthermore, a right sided pyramidal weakness was evident with a right upper-motor facial nerve palsy. Reflexes were diminished and plantars were bilaterally extensor. There was neck stiffness with a positive Kernig sign. Her optic fundi were normal with no haemorrhages or papilloedema.

Serum IgM and IgG antibodies were positive for dengue. Serum transaminases were slightly elevated with normal bilirubin. She had mild hypocalcaemia but its correction did not change the clinical condition. Other electrolytes, random blood glucose and the serum creatinine levels remained normal throughout. The lowest platelet count was $27 \times 109 / /$. Magnetic resonance imaging of the head was normal. The electroencephalogram showed generalised delta and theta slowing. The CSF report showed neutrophils $55 / \mathrm{mm}^{3}$, lymphocytes $45 / \mathrm{mm}^{3}$, red cells $550 / \mathrm{mm}^{3}$, protein $174 \mathrm{mg} / \mathrm{dl}$ and normal sugar. Gram stain and culture of CSF was negative as were the blood cultures. Dengue IgM was positive in CSF. Japanese encephalitis and herpes simplex virus antibodies were not detected in CSF. She was treated with intravenous mannitol, acyclovir, cefotaxime and vancomycin as the physical signs at the outset suggested bacterial meningitis. Anti epileptics and supportive care were given and she was managed in the intensive care unit. She showed no evidence of leakage throughout her stay and was stable haemodynamically. She remained in this state for the next 7 days before beginning to improve neurologically. She made a steady and uneventful recovery gaining full power on the right side of her body and was alert and orientated with normal cognition on the twelfth day after the neurological deterioration. This case is reported to highlight the wide spectrum of manifestations of dengue infection.

\section{References}

1. Malavige GN, Ogg G. Pathogenesis of severe dengue infection. Ceylon Medical Journal 2012; 57: 97-100.

2. Lum LC, Lam SK, Choy YS, et al. Dengue encephalitis: a true entity? American Journal Tropical Medicine Hygiene 1996; 54: 256-9.

\section{D Ranasinghe, A Kulathunga, R D N C Sarathchandra, S T C J Subasinghe \\ Medical Unit, National Hospital, Sri Lanka. \\ Correspondence: LDR, e-mail: <lalana.devi@gmail.com>. Received 6 September 2012 and revised version accepted 18 December 2012. Competing interests: none declared.}

